\title{
Current status of advanced gastrointestinal endoscopy training fellowships in the United States
}

Stephen J Heller

Jeffrey L Tokar

Department of Medicine, Fox Chase Cancer Center, Philadelphia, PA, USA

Correspondence: Stephen J Heller Department of Medicine, Fox Chase Cancer Center, 333 Cottman Avenue, Philadelphia, PA I9III, USA

Tel + I 2I5 2I 4 I424

Fax +I 2152141425

Email stephen.heller@fccc.edu
This article was published in the following Dove Press journal:

Advances in Medical Education and Practice

10 January 2011

Number of times this article has been viewed

Abstract: Rapid growth in the field of advanced gastrointestinal endoscopy has led to an increase in specialized therapeutic endoscopy fellowships. The cornerstones of these programs are training in endoscopic retrograde cholangiopancreatography (ERCP) and endoscopic ultrasound. These procedures are more complex and challenging to master than routine colonoscopy and upper endoscopy, and in the case of ERCP, higher risk. The concentration of the educational experience in the hands of relatively fewer trainees with specialized interest in advanced endoscopy has resulted in providing a focused cohort of graduating fellows with higher case volumes in training, which likely enhances diagnostic and therapeutic success and safer performance of these procedures. Endoscopic simulators, although not currently in widespread use, have the potential to improve advanced procedural training without jeopardizing patient safety.

Keywords: gastrointestinal endoscopy, training, procedures, safety

\section{Introduction}

The last two decades has seen a remarkable growth in advanced endoscopic training programs in the United States. There are many reasons for this development. As the practice of endoscopy has evolved, procedures have become more complex. Many of these procedures are higher risk than routine colonoscopy and upper gastrointestinal (GI) endoscopy. Given the increased complexity and potential morbidity of these endoscopic techniques and the attendant concern about adverse outcomes and potential medicolegal ramifications, the natural evolution has been the concentration of these procedures in high-volume tertiary referral centers with specialized expertise. The equipment required to perform these procedures is often expensive and economically impractical for many community-based practices or hospitals with relatively low advanced endoscopy case volumes. Finally, many of these techniques (endoscopic ultrasound [EUS] is a prime example) serve as a bridge to complex surgery, organ transplantation, or treatment of uncommon malignancies, therapies usually performed in a tertiary facility. It makes sense, therefore, that the endoscopic procedures that are closely linked with these highly complex therapies be performed at the same institutions. Fellowships in advanced endoscopic procedures are not accredited by the Accreditation Council for Graduate Medical Education (ACGME) in the United States, and completion of additional training is not required to obtain hospital privileges for performing such procedures. Nonetheless, these fellowships are coveted by graduating gastroenterology fellows with an interest in therapeutic endoscopy.

The procedures that comprise the 'curriculum' of many advanced endoscopy fellowships are listed in Table 1. Some programs offer extensive training in only one procedure 
Table I Procedures taught in advanced endoscopy training fellow ships in the United States

ERCP

EUS

Advanced colon polypectomy

EMR

Endoscopic therapy of Barrett's esophagus

Esophageal and enteral stent placement

Device-assisted enteroscopy including DAE-ERCP

Endoscopic drainage of pancreatic pseudocysts

Endoscopic removal of neoplasms of the ampulla of Vater

Abbreviations: ERCP, endoscopic retrograde cholangiopancreatography; EUS, endoscopic ultrasound; EMR, endoscopic mucosal resection; DAE, device-assisted enteroscopy.

(eg, endoscopic retrograde cholangiopancreatography [ERCP]), while others provide a wider breadth of exposure to some or all of these procedures. The objective of this review is to provide the nongastroenterologist with a general perspective on the current practice and training of advanced endoscopic procedures in the United States.

\section{ERCP}

Initially a diagnostic procedure, ERCP in today's practice is primarily therapeutic; this is largely due to the advent of noninvasive modalities to image the pancreatic and bile ducts (eg, magnetic resonance cholangiopancreatography). Clinical indications for ERCP include removal of gallstones from the common bile duct, palliative stent placement for jaundice resulting from malignant biliary obstruction, treatment of bile duct leaks complicating biliary surgery such as cholecystectomy, and therapy for chronic pancreatitis (dilation of pancreatic duct stenoses, removal of obstructing pancreatic duct stones, and placement of pancreatic duct stents). ${ }^{1}$ The American Society for Gastrointestinal Endoscopy (ASGE) has published a formalized ERCP core curriculum, ${ }^{2}$ which delineates the essential components of proficiency in ERCP: adequate preprocedure fund of knowledge and risk assessment, recognition and management of common complications, passage of the duodenoscope used for ERCP in normal and surgically altered anatomy, selective cannulation of the desired (bile or pancreatic) ducts, cholangiography and pancreatography, sphincterotomy, tissue sampling, stricture dilation, and stent placement.

ERCP is one of the first procedures to be considered as 'advanced endoscopy'. Indeed, fellowships in advanced endoscopy were developed in large measure to provide a dedicated subgroup of trainees with concentrated exposure to this demanding procedure. Although it has been in widespread use for more than 30 years, ERCP still commands respect among clinicians for its technical difficulty and morbidity. ERCP with biliary sphincterotomy carries an approximate $5 \%$ risk of acute pancreatitis, a $1 \%-2 \%$ risk of transfusionrequiring hemorrhage, a $0.3 \%$ risk of bowel perforation, and a $0.4 \%$ mortality rate. Patient characteristics, such as suspected sphincter of Oddi dysfunction or cirrhosis, and technical aspects of a procedure (ie, difficulty cannulating the bile duct, use of particularly invasive techniques such as 'precut' sphincterotomy, and endoscopic-radiologic rendezvous procedure) were associated with higher complication rates in the multivariate analysis. ${ }^{3}$ However, in another multicenter study, trainee involvement in the procedure was associated with an increased risk of developing postERCP pancreatitis, as were $\geq 2$ injections in the pancreatic duct (considered by many to be a rough marker of limited technical expertise). ${ }^{4}$

Both trainees and attending physicians have expressed concern regarding suboptimal training during the course of general gastroenterology fellowship. In a survey of graduating fellows, one-third of respondents stated that they received inadequate ERCP training during their fellowship. Despite this perception of inadequate training, greater than 90\% stated they would be performing ERCP independently as attending physicians. ${ }^{5}$ There is ample evidence supporting the notion that competence in ERCP is achieved only after a substantial number of cases have been performed. A landmark study by Jowell and colleagues showed that at least 180 ERCPs were necessary for the fellow to attain a level of competence defined by the authors. ${ }^{6}$ Other authors cite 200 procedures as a threshold for competence in ERCP. ${ }^{7} \mathrm{~A}$ recent study evaluated the procedural competence of one fellow over the course of training. The provocative findings of this paper suggested that using $>80 \%$ selective cannulation rate as a benchmark for competence, $350-400$ cases were required to achieve proficiency. ${ }^{8}$ It is difficult, if not impossible, for all graduating gastroenterology fellows to perform this volume of cases during training.

The ERCP core curriculum addresses this quandary, stating 'While all fellows should have exposure to these techniques, comprehensive ERCP training to a level of competence for independent practice should be limited to programs with sufficient case volume, expertise, and trainee interest'. ${ }^{2}$ Although additional training beyond general gastroenterology fellowship is not a prerequisite to perform ERCP independently, many experts feel that such additional training should, in fact, be mandatory. ${ }^{9}$ The general perception that fellows who have graduated from advanced training programs can perform ERCP with higher success rates and 
lower rates of complications has enhanced the popularity of these programs.

Endoscopic simulators have been created as training aids for cannulation of the bile or pancreatic duct, sphincterotomy, extraction of bile duct stones, and stent placement. Simulators can be based on live animals, harvested animal organs, computer-generated (virtual) models, or mechanical constructs. ${ }^{10-13}$ Considerable attention has been focused on endoscopic simulators as a potential way to increase 'hands-on' exposure to a large number of endoscopic trainees without putting patients at increased risk. In a study of 20 attending endoscopists comparing a computer model, harvested porcine organs, and live anesthetized pigs, the computer model was deemed the easiest to incorporate into a training program, though the harvest porcine organs received the highest scores for 'ease of use'. ${ }^{14}$

Barriers to widespread use of animal models include ethical concerns, cost (procurement of animals and anesthesia), and inefficiency. Differences between porcine and human anatomy may also limit the utility of the Erlangen model as a realistic simulator. The Neo-Papilla, an ERCP simulator which is fashioned from porcine blood vessels and chicken cardiac tissue sewn into a harvested pig duodenum, may be a better anatomic representation of human anatomy and can be used by multiple trainees. ${ }^{11}$ Widespread adoption of computer simulators, on the other hand, is hampered by cost (US\$60,000-80,000) ${ }^{14}$ and a perceived lack of realism. ${ }^{11,14}$

A recent study using a mechanical simulator suggests it may be a useful educational tool. In this multicenter trial, 16 trainees were randomized following routine ERCP didactic sessions to practice on a mechanical simulator versus no simulator use. Over the ensuing 16 weeks, fellows who had practiced on the mechanical simulator demonstrated shorter time to cannulation and higher rates of successful cannulation. ${ }^{15}$ The results of this small but provocative study underscore the need for continued investigation in this area.

While simulators might help overcome the conundrum of insufficient ERCP case volumes in many centers relative to the large numbers of trainees interested in acquiring the requisite skills, additional evidence is required before simulators assume a mainstream role in ERCP training. Even if such evidence becomes available, a paradigm shift in the approach to ERCP training will be necessary in order for simulators to gain widespread acceptance.

Training the advanced fellow in ERCP is a challenging task. The most difficult aspect of ERCP is learning safe and expeditious cannulation of the bile duct. The endoscopist's armamentarium for this task includes the use of multiple endoscopic accessories and techniques. ${ }^{16,17}$ The attending physician needs to allow the fellow sufficient 'hands-on' experience to develop proficiency, while not sacrificing patient safety. Other factors that come into consideration are time efficiency and cost-effectiveness. The novice fellow may expend valuable time in the endoscopy unit, resulting in more lengthy procedures that consume greater resources, including the costs associated with anesthesia, nursing care, and additional disposable accessories. In our unit, and we suspect in most advanced fellowships nationwide, the fellow is given increased 'hands-on' experience over the course of the year. The objective is for the trainee to become proficient in selective cannulation of the bile duct and pancreatic duct (in routine and difficult cases), biliary and pancreatic sphincterotomy, tissue sampling within the pancreaticobiliary tree, and a variety of therapeutic interventions (eg, stricture management, placement of plastic and metal stents, and stone extraction).

\section{EUS}

EUS is a modality that utilizes endoscopic techniques to position different types of ultrasound transducers in the GI tract, enabling sonographic visualization of each layer of the GI tract wall (eg, mucosa, submucosa, muscularis propria) as well as extraintestinal structures (eg, liver, pancreas, lymph nodes). Coupled with innovations that enable the endoscopist to also perform fine needle aspiration under EUS guidance (EUS-FNA), the technique has had a major impact on the field of GI endoscopy. Since its introduction into clinical practice, EUS has assumed an important role in cancer staging as well as evaluation and management of various pancreatic and biliary disorders, nonepithelial GI tract mass lesions, and tissue sampling of extra-intestinal pathology such as lymphadenopathy.

Performing EUS competently requires technical and cognitive abilities beyond the scope of conventional endoscopy. For example, it necessitates a greater understanding of human cross-sectional anatomy in multiple axes of orientation (axial, sagittal), knowledge of ultrasonography, and technical proficiency in techniques that are not learned during conventional endoscopy training. The ASGE therefore recommends that credentialing for EUS be determined independently from any other endoscopic procedure and provides recommendations for the minimum number of supervised EUS procedures required to gain competency. Formal training and increasing experience with EUS have been shown to 
correlate with diagnostic accuracy. ${ }^{18-24}$ While the absolute number of supervised procedures required for competency in various aspects of EUS remains unknown, the ASGE Standards of Practice Committee on credentialing in EUS recommends a minimum of 100 supervised cases for trainees interested in evaluating only mucosal and submucosal GI tract pathology. For trainees pursuing more comprehensive competence in EUS, a minimum of 150 supervised EUS cases was recommended, of which 75 should be pancreaticobiliary, and 50 should include fine needle aspiration. ${ }^{25} \mathrm{~A}$ combined ASGE/ACG (American College of Gastroenterology) task force developed a set of preprocedural, intraprocedural, and postprocedural 'quality indicators' to aid in the recognition of high-quality EUS examinations. ${ }^{26}$

Currently, many endoscopists performing EUS in the United States have completed some form of advanced endoscopic training. ${ }^{27}$ However, completion of an advanced endoscopy fellowship in EUS is not mandated, and data regarding the adequacy of EUS training in the United States are limited. Azad et al recently reported results from a survey on EUS training that was administered to American gastroenterology fellowship training program directors. ${ }^{28}$ They found that although $86 \%$ of programs surveyed provide some EUS training for their traditional 3-year GI fellows, their exposure to EUS varied greatly; more than half (55\%) trained their fellows in EUS for fewer than 3 months, and the exposure to EUS was low, with a median of only 50 cases (range $0-350$ ). Seventy-four percent of 3-year GI fellows completed their training having participated in fewer than 75 EUS procedures, below the competency minimum recommended by the ASGE. The median number of EUS procedures performed by 4 th year advanced endoscopy fellows was 200 (range, $50-1100$ ), but only $48 \%$ of all advanced fellows met the ASGE recommendations for minimum number of procedures. This and other studies ${ }^{27,29}$ suggest that many 3-year GI fellows and even 4th year advanced fellows may be receiving insufficient training in EUS relative to the ASGE guidelines. Nevertheless, there is a significant correlation between the number of total upper EUS examinations, pancreaticobiliary examinations, and EUS-guided FNA and completion of an advanced endoscopy fellowship. ${ }^{27}$

'Hands-on' participation in EUS training is superior to passive observation alone. ${ }^{18,28}$ However, as with ERCP, the uncertainty about whether case volumes in GI training programs are adequate to establish competency for all trainees interested in performing EUS has promoted interest in developing novel training paradigms. One paradigm involves use of mechanical simulators (Erlangen Endo-Trainer; ECE,
Erlangen-Nuremberg, Germany), computerized virtual simulators (eg, GI Mentor ${ }^{\mathrm{TM}}$; Simbionix USA Corp., Cleveland, $\mathrm{OH}$ ), and/or use of live animals (eg, porcine models). These are increasingly being utilized at one-time 'hands-on' endoscopy courses that trainees can choose to attend. While there is some support for these methods, ${ }^{30-33}$ like ERCP simulators, they remain largely unused by training programs due to concerns about cost, resource utilization, ethical considerations, and a paucity of evidence that use of these simulated models translates into quantifiable differences in clinical outcomes compared with conventional supervised training in human patients (eg, improvements in EUS competency, EUS safety, patient comfort during EUS procedures).

In recent years, the term 'Interventional EUS (i-EUS)' has been used to describe procedures that combine EUS-FNA techniques with various advanced ERCP skills (eg, interpretation of real-time fluoroscopy images, proficiency with ERCP catheters and guidewires). It is considered by some to be the 'next frontier' in GI endoscopy. Although a detailed review of i-EUS is beyond the scope of this publication and has been described elsewhere, ${ }^{34-36}$ it merits mention since the vast majority of i-EUS training in the foreseeable future will occur in academic institutions with advanced endoscopy training programs. Examples of i-EUS procedures include endoscopic drainage of pancreatic pseudocysts or other extra-intestinal fluid collections, celiac plexus neurolysis for treatment of cancer-related pain, placement of fiducials to facilitate cancer radiotherapy, and management of bile duct or pancreatic duct obstruction that cannot be managed using conventional ERCP techniques. Potentially therapeutic i-EUS procedures, still undergoing clinical investigation, include EUS-guided delivery of cytotoxic agents into tumors, ethanol ablation of cystic neoplasms of the pancreas, and creation of enteric anastomoses in patients with malignant bowel obstruction not amenable to enteral stenting.

\section{Enteral stents}

Esophageal and enteral stents have become a popular modality for palliation in patients with malignancy and symptoms due to obstruction. The use of stents was recently reviewed in a Technology Status Evaluation Report from the ASGE. ${ }^{37}$ These stents are composed of either stainless steel or alloys of nickel, titanium, cobalt, and chromium, or self-expanding plastic. They are inserted into the GI tract across the obstruction via small-caliber delivery systems, but once these endoprostheses are deployed, they expand to larger diameters, allowing passage of GI contents and thereby alleviating symptoms of obstruction. Evidence has demonstrated safety and efficacy 
in the placement of these stents in the esophagus for treatment of malignant stenoses and tracheoesophageal fistulas (TEFs). Covered stents, which have a thin membrane covering the interstices of the stent that prevents luminal contents and tumor from penetrating through the interstices, are preferred for palliation of TEF. ${ }^{38}$ Stents are effective for palliation of malignant obstruction of the duodenum, ${ }^{39}$ distal stomach, ${ }^{40}$ and colorectum. ${ }^{41}$ In addition, colonic stents can be used as a bridge to surgery in patients who present with malignant large bowel obstruction, sparing some patients from surgery which, in an unprepped colon, often requires formation of a colostomy. ${ }^{42}$ Esophageal stents are also increasingly utilized for temporary palliation of malignant dysphagia for patients with locally advanced but potentially resectable esophageal cancer, enabling them to maintain their nutritional status while they undergo neoadjuvant chemoradiation. The stent can subsequently be removed prior to esophagectomy. ${ }^{43}$ In general, esophageal and enteral stents are highly effective when used in appropriately selected patients, and are technically feasible in the majority of cases. However, they can be associated with serious complications such as bleeding, bowel perforation, and airway compromise. ${ }^{37}$

The ability to place these stents has become part of the therapeutic armamentarium for the advanced endoscopist. They are typically placed under direct endoscopic and fluoroscopic control. Proficiency in this procedure requires a comfort level in the deployment of metal stents which is typically acquired from training in ERCP, where these devices are deployed more commonly. Expertise in the judicious use of fluoroscopy in conjunction with endoscopy is essential. Fellows are trained in careful pre-procedure evaluation of the patient, including assessment of comorbidities which would adversely impact procedural risk as well as the risk-benefit ratio of stent placement relative to other potential treatment options, such as surgery, chemoradiation, or other endoscopic modalities. The trainee learns the importance of familiarizing oneself with the stent and its deployment system prior to the procedure, in order to avoid potentially harmful and costly mistakes during the actual procedure. During the endoscopy itself, fellows are instructed in the precise identification of the anatomic margins of the bowel stenosis, and methodical, patient deployment of the stent under direct fluoroscopic visualization, and whenever possible, simultaneous endoscopic visualization.

\section{Advanced colon polypectomy}

Colonoscopy with routine polypectomy is a cornerstone in the practice of a general gastroenterologist and does not require additional training. For fellowships in gastroenterology, the ACGME mandates that fellows perform 140 supervised colonoscopies and 30 supervised polypectomies. ${ }^{44}$ Removal of typical colorectal polyps should not pose a challenge for the graduating gastroenterology fellow. However, endoscopic removal of large or complex colorectal polyps (or polyps elsewhere in the GI tract) is perceived as high-risk, and these cases are frequently referred to specialty referral centers. Thus, another common procedure in some advanced endoscopy training programs is removal of challenging polyps.

Advanced polyp resection, defined by the ASGE Colonoscopy Core Curriculum as removal of a polyp $>2 \mathrm{~cm}$ in diameter may pose a technical challenge. ${ }^{45}$ Other experts have expanded the definition of advanced polypectomy to include difficult location (the cecum, angulated bowel, astride two or more folds), poorly visualized lesions, and broad sessile or flat lesions. ${ }^{46}$ Removal of larger polyps (polyps $>1 \mathrm{~cm}$ in the right colon, $>2 \mathrm{~cm}$ in the left colon) carried an increased risk of major complications in a large, prospective European study of nearly 4000 snare polypectomies. ${ }^{47}$ There is also the concern that removal of large polyps in the right colon is more hazardous because this section of the colon is relatively thin-walled and at higher risk for transmural perforation.

Although these polyps are more challenging to remove, the data support a vigorous effort to remove them endoscopically to avert the need for surgical resection. In a series of 252 patients with large polyps who were referred to colorectal surgeons experienced in advanced polypectomy, $101 / 250$ (40\%) underwent curative endoscopic polypectomy that obviated the need for surgery. ${ }^{48}$ In a recent study from Australia, 90\% of 174 patients referred with 'refractory' colon polyps could actually be treated endoscopically with advanced polypectomy techniques, thereby avoiding surgery. There were no perforations. The authors pointed out that endoscopic therapy not only spared patients the morbidity of surgery, but was also cost-effective. ${ }^{49}$

Although these lesions are technically more challenging and time-consuming to remove, and carry a higher risk of complications, it is usually worth the considerable effort to remove them endoscopically. In many advanced endoscopy programs (including ours), fellows gain technical expertise in removal of large, difficult colorectal polyps. The technique of 'piecemeal' polypectomy, which is recommended for sessile polyps $>2 \mathrm{~cm},{ }^{46}$ is emphasized. The trainee develops proficiency in the use of the 'toolbox' that is used in advanced polypectomy. These tools include submucosal injection with a sclerotherapy needle, usually with either normal saline or 
dilute epinephrine, to 'lift' the polyp and create a submucosal cushion which is believed to reduce the risk of perforation. In addition, the trainee gains familiarity with a broad array of polypectomy snares, detachable endoscopic loops and hemostatic clips. It is difficult to predict which of these devices will be used in a particular case, so timely access to the equipment and ready proficiency among physicians and assistants alike in the use of each of these devices is mandatory. Our fellows also become familiar with the use of the argon plasma coagulator as an adjunctive tool in advanced polypectomy, as it may be useful in eradicating small areas of residual adenomatous tissue following snare polypectomy of a large, sessile polyp. ${ }^{50}$

\section{Endoscopic therapy of Barrett's esophagus}

The incidence of adenocarcinoma of the esophagus has risen dramatically, ${ }^{51}$ and a critical precursor of this cancer is Barrett's esophagus. ${ }^{52}$ Recent developments have greatly improved the endoscopist's ability to treat dysplasia or early stage malignancy (ie, intramucosal cancer) in patients with Barrett's esophagus. Several lines of evidence suggest that in carefully selected patients, endoscopic interventions can cure early stage Barrett's neoplasia. As of this writing, two of the most well studied and widely utilized endoscopic therapeutic modalities in this setting are radiofrequency ablation (RFA) and endoscopic mucosal resection (EMR). A recent multicenter, randomized, sham-controlled study evaluating RFA for treatment of dysplastic Barrett's demonstrated $81 \%$ eradication of high-grade dysplasia at 12 months in the RFA treatment group versus $9 \%$ in the sham group. An acceptable safety profile was observed without any life-threatening complications. ${ }^{53}$ In a series of 100 consecutive patients with early esophageal cancer, EMR was successful in achieving local remission in 99/100 cases. Cancer recurred in $11 \%$, but was successfully re-treated endoscopically in all cases. No severe complications such as perforation were observed. ${ }^{54}$ Recent data suggest that a combination of endoscopic therapies may be optimal; that is, endoscopic removal of any visible dysplastic nodules with EMR, followed by endoscopic eradication of the remaining Barrett's esophagus with RFA. ${ }^{55}$ Although RFA has also been proven effective for eradication of nondysplastic Barrett's esophagus, ${ }^{56}$ endoscopic treatment for nondysplastic Barrett's remains controversial and requires further study to determine the durability of the treatment response, the long-term cancer risk reduction, and the cost-effectiveness of this strategy.
The low complication rates of these studies notwithstanding, it is our impression that the majority of these procedures are performed in tertiary referral centers. It is important to emphasize that EMR is an operator-dependent procedure with the potential for serious adverse events. Even in experienced centers, perforation rates from EMR have been reported as high as $2.5 \% .{ }^{57}$ When perforation occurs, treatment often entails skilled use of cutting-edge endoscopic modalities such as endoscopic clips or covered esophageal stent placement. Experts agree that EMR is difficult to master and associated with a significant learning curve. ${ }^{58}$ There is no published literature evaluating the learning curve for EMR in the esophagus. One Korean study assessing the learning curve for EMR in the treatment of early gastric cancer found that 40 cases were required for the acquisition of safe, effective technique. ${ }^{59}$

Although probably safer than EMR, RFA is also perhaps best suited to the tertiary setting, owing to the significant cost of the equipment and the linkage of advanced endoscopy with high-volume esophageal surgery programs in many referral centers. We believe that the role of these and similar modalities will expand as the incidence of adenocarcinoma of the esophagus continues to rise and we improve our ability to identify patients with early stage lesions amenable to endoscopic therapy.

In institutions performing endotherapy of dysplastic Barrett's esophagus, fellows become proficient in RFA and EMR, as well as other endoscopic modalities such as cryoablation, under the direct supervision of attending physicians with experience in these procedures. Trainees learn to perform careful inspection for any anatomic abnormalities within a Barrett's segment prior to undertaking any therapeutic maneuvers. Proficiency in Barrett's endotherapy requires not only competence in the treatment modalities themselves, but also the ability to treat potential complications such as hemorrhage and perforation with endoscopic techniques.

\section{Deep small bowel enteroscopy}

The last decade has ushered in a revolution in endoscopic access to the small bowel. Routine endoscopic procedures (upper GI endoscopy, colonoscopy, and 'push' enteroscopy) enable endoscopists to examine the duodenum, terminal ileum, and proximal jejunum, respectively. With the advent of the small bowel video capsule in $2000,{ }^{60}$ clinicians have gained the ability to visualize the mucosa of the entire length of the small bowel. The capsule allows the clinician to visualize the small intestinal mucosa in its entirety, but it offers no therapeutic capability. Newer modalities such as 
single-balloon enteroscopy (SBE) (Olympus America Inc, Center Valley, PA), double-balloon enteroscopy (DBE) (Fujinon Inc, Wayne, NJ), and spiral-assisted enteroscopy (Spirus Medical, Stoughton, MA,) enable the endoscopist to reach and directly visualize most, if not all, of the jejunum and ileum. ${ }^{61,62}$ We refer to these technologies, collectively, as device-assisted enteroscopy (DAE). Direct endoscopic access to the deep small bowel has enabled removal of polyps, treatment of bleeding vascular lesions, dilation of small bowel stenoses, removal of foreign bodies, and endoscopic tattooing of small bowel tumors to facilitate surgical removal. The small bowel can be reached with these techniques through either an anterograde (per os) or retrograde (per rectum) approach. Of these technologies, DBE is the most established, with the largest body of evidence supporting its utility and safety. ${ }^{63}$

The most common use of these techniques is in the diagnosis and management of obscure GI bleeding, defined as bleeding with the source not identified by upper GI endoscopy and colonoscopy. In clinical practice, most patients with obscure GI bleeding first undergo capsule endoscopy. Once a small bowel capsule study identifies an abnormality, DAE is performed to identify, characterize, and potentially treat the pathology. A recent review by the ASGE of the endoscopic management of obscure GI bleeding recommends consideration of deep small bowel enteroscopy in both overt (ie, gross evidence of GI bleeding such as melena) and occult GI bleeding. ${ }^{64}$ In this clinical scenario, angioectasias (AVMs) of the small bowel are the most common culprit. In a US study of 137 patients who underwent DBE, most of whom were evaluated for GI bleeding of a suspected small bowel source, nearly half were found to have vascular abnormalities in the small bowel such as AVMs. ${ }^{65}$ Although long-term outcomes data assessing the impact of endoscopic treatment of small bowel AVMs or other sources of small bowel bleeding are limited, a recent study reported that approximately half of patients treated for small bowel AVMs by DBE were free of bleeding at 30 months. ${ }^{66}$

DAE has also greatly enhanced the endoscopist's ability to identify small bowel polyps and tumors. In a European series, nearly $10 \%$ of DBEs yielded a diagnosis of small bowel polyp or tumor. The most common findings were adenomas in patients with familial adenomatous polyposis, hemartomas, jejunal adenocarcinomas, and neuroendocrine tumors. ${ }^{67}$ In patients with ongoing or recurrent bleeding of a suspected small bowel source, a negative capsule endoscopy study does not necessarily preclude further evaluation of the small intestine using one of the DAE methods, because there are several reports of lesions (including malignancies) missed by capsule endoscopy but subsequently detected by DAE. ${ }^{68,69}$

DAE has also proven valuable in reaching the pancreaticobiliary tree in some patients with altered surgical anatomy. The most common scenario requiring DAE for this indication is following Roux-en-Y reconstruction, a surgery performed during some cancer resections, bariatric surgery, and liver transplantation. In these patients, the length of bowel required to reach the pancreaticobiliary tree cannot be traversed with standard endoscopes. DAE has made ERCP and endoscopic biliary interventions feasible in many of these patients, in whom such interventions were previously difficult if not impossible. $^{70}$

DAE has added to the armamentarium of the advanced endoscopist. In contrast to the more technically demanding ERCP and EUS, the learning curve at least for DBE appears to be shorter. ${ }^{71}$ Nonetheless, it is our impression that these procedures are typically performed at tertiary centers. In comparison to routine upper GI endoscopy and colonoscopy, these procedures are time consuming and difficult for busy clinicians to accommodate into their schedules. Performing removal of large polyps and endoscopic hemostasis deep within the small bowel requires proficiency in advanced endoscopic skills, and can be especially challenging due to impaired leverage and maneuverability. The additional cost of obtaining the necessary equipment is another barrier to widespread use. For example, use of DBE requires dedicated Fujinon enteroscopes, processors, and specific accessories which are not widely available.

Our institution is a referral center for endoscopy of the small bowel, and we perform more than 200 DBEs annually. We are also proficient in spiral-assisted enteroscopy. Our fellows gain an understanding of the indications for these techniques and also become skilled in the performance of these procedures. In accordance with the published data, we find that fellows acquire competence in DBE more readily than in ERCP and EUS. We anticipate that the role of the therapeutic endoscopist in management of disorders of the small bowel will continue to grow, as primary physicians and gastroenterologists become increasingly aware of the clinical value of DAE, and we see further refinement of the endoscopic tools at our disposal.

\section{Future directions}

GI endoscopy continues to evolve, shaped by dramatic innovations in endoscopes, endoscopic imaging modalities, and accessories. A prime example is natural orifice transluminal 
endoscopic surgery (NOTES). In NOTES procedures, the endoscopist makes an intentional perforating incision in the wall of the GI tract (eg, stomach or colon) and accesses the peritoneal cavity with an endoscope through that incision. This enables the endoscopist to perform interventions historically feasible only via percutaneous approaches, such as cholecystectomy or tubal ligation. After the procedure, the perforating incision is 'closed' with endoscopic techniques, and the endoscope is withdrawn, resulting in essentially 'scarless' surgery. While the clinical utility of NOTES remains to be seen, it has generated interest in the biotechnology industry in the development of new endoscopic devices. We are optimistic that this infusion of enthusiasm and resources will contribute to better endoscopic accessories, which will nourish the practice of therapeutic endoscopy, regardless of whether NOTES becomes part of standard clinical care.

Along with these advances in endoscopy, innovations are taking place in noninvasive imaging and diagnostic tests (eg, CT-colonography or 'virtual colonoscopy', fecal DNA tests for colorectal neoplasms). These noninvasive techniques, in theory, have the potential to reduce the future demand for routine endoscopic procedures. The perceived implications of these changes, and the ongoing desire among general GI fellows to maximize their future marketability and career opportunities, will ensure the continued success of advanced endoscopy programs. A recent report of the Multisociety Task Force on GI Training concluded that advanced training could be included in the final 18 months of a conventional GI fellowship or could be completed in an additional fourth year of training. ${ }^{72,73}$ Nevertheless, there are many unanswered questions pertaining to advanced endoscopy procedures and training programs in the United States that warrant attention. Examples include:

1. What is the estimated future demand for various advanced procedures, and how many graduates of advanced programs are needed to meet these demands?

2. What is the most cost-effective way to provide training for an adequate number of endoscopists to meet these demands?

3. How adequate are existing guidelines regarding the number of advanced procedures suggested for trainees to be considered competent to perform the procedure independently? Should performance of emerging advanced procedures be standardized and regulated, and if so, how is this best accomplished?

4. What are the optimal methods for measuring and monitoring the overall progress of advanced endoscopy trainees?
Similarly, should the competence of faculty mentors be routinely monitored, and if so, how?

5. What is the best way to incorporate teaching of the less common but more complex endoscopic procedures into training programs (eg, EUS-guided interventions, ERCP in patients with surgically altered GI anatomy, NOTES procedures)?

6. Does the use of endoscopic simulators during training translate into improved clinical outcomes (eg, greater technical and cognitive understanding of a procedure, lower complication rates, and increased cost-effectiveness)? If so, should they be routinely incorporated into advanced endoscopy training?

\section{Disclosure}

The authors report no conflicts of interest in this work.

\section{References}

1. Adler DG, Baron TH, Davila RE, et al. ASGE guideline: the role of ERCP in diseases of the biliary tract and the pancreas. Gastrointest Endosc. 2005;62(1):1-8.

2. Chutkan RK, Ahmad AS, Cohen J, et al. ERCP core curriculum. Gastrointest Endosc. 2006;63(3):361-376.

3. Freeman ML, Nelson DB, Sherman S, et al. Complications of endoscopic biliary sphincterotomy. $N$ Engl J Med. 1996;335(13):909-918.

4. Cheng CL, Sherman S, Watkins JL, et al. Risk factors for post-ERCP pancreatitis: a prospective multicenter study. Am J Gastroenterol. 2006; 101(1):139-147.

5. Kowalski T, Kanchana T, Pungpapong S. Perceptions of gastroenterology fellows regarding ERCP competency and training. Gastrointest Endosc. 2003;58(3):345-349.

6. Jowell PS, Baillie J, Branch MS, Affronti J, Browning CL, Bute BP. Quantitative assessment of procedural competence. A prospective study of training in endoscopic retrograde cholangiopancreatography. Ann Intern Med. 1996;125(12):983-989.

7. Garcia-Cano J. 200 supervised procedures: the minimum threshold number for competency in performing endoscopic retrograde cholangiopancreatography. Surg Endosc. 2007;21(7):1254-1255.

8. Verma D, Gostout CJ, Petersen BT, Levy MJ, Baron TH, Adler DG. Establishing a true assessment of endoscopic competence in ERCP during training and beyond: a single-operator learning curve for deep biliary cannulation in patients with native papillary anatomy. Gastrointest Endosc. 2007;65(3):394-400.

9. Baillie J, Testoni PA. Are we meeting the standards set for ERCP? Gut. 2007;56(6):744-746.

10. von Delius S, Thies P, Meining A, et al. Validation of the X-Vision ERCP Training System and technical challenges during early training of sphincterotomy. Clin Gastroenterol Hepatol. 2009;7(4): 389-396.

11. Matthes K, Cohen J. The Neo-Papilla: a new modification of porcine ex vivo simulators for ERCP training (with videos). Gastrointest Endosc. 2006;64(4):570-576.

12. Neumann M, Mayer G, Ell C, et al. The Erlangen Endo-Trainer: lifelike simulation for diagnostic and interventional endoscopic retrograde cholangiography. Endoscopy. 2000;32(11):906-910.

13. Leung JW, Lee W, Wilson R, Lim BS, Leung FW. Comparison of accessory performance using a novel ERCP mechanical simulator. Endoscopy. 2008;40(12):983-988.

14. Sedlack R, Petersen B, Binmoeller K, Kolars J. A direct comparison of ERCP teaching models. Gastrointest Endosc. 2003;57(7):886-890. 
15. Lim BS, Leung JW, Lee J, et al. Effect of ERCP mechanical simulator (EMS) practice on trainees' ERCP performance in the early learning period: US multicenter randomized controlled trial. Am J Gastroenterol. 2010 Oct 26 [Epub ahead of print].

16. Guda NM, Freeman ML. Are you safe for your patients - how many ERCPs should you be doing? Endoscopy. 2008;40(8):675-676.

17. Freeman ML, Guda NM. ERCP cannulation: a review of reported techniques. Gastrointest Endosc. 2005;61(1):112-125.

18. Meenan J, Anderson S, Tsang S, Reffitt D, Prasad P, Doig L. Training in radial EUS: what is the best approach and is there a role for the nurse endoscopist? Endoscopy. 2003;35(12):1020-1023.

19. Mertz H, Gautam S. The learning curve for EUS-guided FNA of pancreatic cancer. Gastrointest Endosc. 2004;59(1):33-37.

20. Harewood GC, Wiersema LM, Halling AC, Keeney GL, Salamao DR, Wiersema MJ. Influence of EUS training and pathology interpretation on accuracy of EUS-guided fine needle aspiration of pancreatic masses. Gastrointest Endosc. 2002;55(6):669-673.

21. Wiersema MJ, Vilmann P, Giovannini M, Chang KJ, Wiersema LM. Endosonography-guided fine-needle aspiration biopsy: diagnostic accuracy and complication assessment. Gastroenterology. 1997; 112(4):1087-1095

22. Gress F, Schmitt C, Savides T, et al. Interobserver agreement for EUS in the evaluation and diagnosis of submucosal masses. Gastrointest Endosc. 2001;53(1):71-76.

23. Chang KJ. EUS-guided FNA: the training is moving. Gastrointest Endosc. 2004;59(1):69-73.

24. Van Dam J, Brady PG, Freeman M, et al. Guidelines for training in electronic ultrasound: guidelines for clinical application. From the ASGE. American Society for Gastrointestinal Endoscopy. Gastrointest Endosc. 1999;49(6):829-833.

25. Eisen GM, Dominitz JA, Faigel DO, et al. Guidelines for credentialing and granting privileges for endoscopic ultrasound. Gastrointest Endosc. 2001;54(6):811-814

26. Jacobson BC, Chak A, Hoffman B, et al. Quality indicators for endoscopic ultrasonography. Am J Gastroenterol. 2006;101(4):898-901.

27. Wasan SM, Kapadia AS, Adler DG. EUS training and practice patterns among gastroenterologists completing training since 1993. Gastrointest Endosc. 2005;62(6):914-920.

28. Azad JS, Verma D, Kapadia AS, Adler DG. Can US GI fellowship programs meet American Society for Gastrointestinal Endoscopy recommendations for training in EUS? A survey of US GI fellowship program directors. Gastrointest Endosc. 2006;64(2):235-241.

29. Das A, Mourad W, Lightdale CJ, Sivak MV Jr, Chak A. An international survey of the clinical practice of EUS. Gastrointest Endosc. 2004; 60(5):765-770.

30. Barthet M. Endoscopic ultrasound teaching and learning. Minerva Med. 2007;98(4):247-251.

31. Bhutani MS, Hoffman BJ, Hawes RH. A swine model for teaching endoscopic ultrasound (EUS) imaging and intervention under EUS guidance. Endoscopy. 1998;30(7):605-609.

32. Barthet M, Gasmi M, Boustiere C, Giovannini M, Grimaud JC, Berdah S. EUS training in a live pig model: does it improve echo endoscope hands-on and trainee competence? Endoscopy. 2007;39(6): 535-539.

33. Bhutani MS, Aveyard M, Stills HF Jr. Improved model for teaching interventional EUS. Gastrointest Endosc. 2000;52(3):400-403.

34. Sreenarasimhaiah J. Interventional endoscopic ultrasound: the next frontier in gastrointestinal endoscopy. Am J Med Sci. 2009; 338(4):319-324.

35. Ashida R, Chang KJ. Interventional EUS for the treatment of pancreatic cancer. J Hepatobiliary Pancreat Surg. 2009;16(5):592-597.

36. Ramesh J, Varadarajulu S. Interventional endoscopic ultrasound. Dig Dis. 2008;26(4):347-355.

37. Tierney W, Chuttani R, Croffie J, et al. Enteral stents. Gastrointest Endosc. 2006;63(7):920-926.

38. Sharma P, Kozarek R. Role of esophageal stents in benign and malignant diseases. Am J Gastroenterol. 2010;105(2):258-273; quiz 274.
39. Graber I, Dumas R, Filoche B, et al. The efficacy and safety of duodenal stenting: a prospective multicenter study. Endoscopy. 2007; 39(9):784-787.

40. Mosler P, Mergener KD, Brandabur JJ, Schembre DB, Kozarek RA. Palliation of gastric outlet obstruction and proximal small bowel obstruction with self-expandable metal stents: a single center series. J Clin Gastroenterol. 2005;39(2):124-128.

41. Sebastian S, Johnston S, Geoghegan T, Torreggiani W, Buckley M. Pooled analysis of the efficacy and safety of self-expanding metal stenting in malignant colorectal obstruction. Am J Gastroenterol. 2004; 99(10):2051-2057.

42. Martinez-Santos C, Lobato RF, Fradejas JM, Pinto I, Ortega-Deballon P, Moreno-Azcoita M. Self-expandable stent before elective surgery vs emergency surgery for the treatment of malignant colorectal obstructions: comparison of primary anastomosis and morbidity rates. Dis Colon Rectum. 2002;45(3):401-406.

43. Langer FB, Schoppmann SF, Prager G, et al. Temporary placement of self-expanding oesophageal stents as bridging for neo-adjuvant therapy. Ann Surg Oncol. 2010;17(2):470-475.

44. Accreditation Council for Graduate Medical Education (ACGME). ACGME program requirements for graduate medical education in gastroenterology. 2007.

45. ASGE Committee on Training. Colonoscopy Core Curriculum. Oak Brook, IL: American Society for Gastrointestinal Endoscopy; 2001.

46. Monkemuller K, Neumann H, Fry LC, Ivekovic H, Malfertheiner P. Polypectomy techniques for difficult colon polyps. Dig Dis. 2008;26(4): 342-346.

47. Heldwein W, Dollhopf M, Rosch T, et al. The Munich Polypectomy Study (MUPS): prospective analysis of complications and risk factors in 4000 colonic snare polypectomies. Endoscopy. 2005; 37(11):1116-1122.

48. Voloyiannis T, Snyder MJ, Bailey RR, Pidala M. Management of the difficult colon polyp referred for resection: resect or rescope? Dis Colon Rectum. 2008;51(3):292-295.

49. Swan MP, Bourke MJ, Alexander S, Moss A, Williams SJ. Large refractory colonic polyps: is it time to change our practice? A prospective study of the clinical and economic impact of a tertiary referral colonic mucosal resection and polypectomy service (with videos). Gastrointest Endosc. 2009;70(6):1128-1136.

50. Zlatanic J, Waye JD, Kim PS, Baiocco PJ, Gleim GW. Large sessile colonic adenomas: use of argon plasma coagulator to supplement piecemeal snare polypectomy. Gastrointest Endosc. 1999;49(6):731-735.

51. Pohl H, Welch HG. The role of overdiagnosis and reclassification in the marked increase of esophageal adenocarcinoma incidence. $J$ Natl Cancer Inst. 2005;97(2):142-146.

52. Pera M. Epidemiology of esophageal cancer, especially adenocarcinoma of the esophagus and esophagogastric junction. Recent Results Cancer Res. 2000;155:1-14.

53. Shaheen NJ, Sharma P, Overholt BF, et al. Radiofrequency ablation in Barrett's esophagus with dysplasia. N Engl J Med. 2009; 360(22):2277-2288.

54. Ell C, May A, Pech O, et al. Curative endoscopic resection of early esophageal adenocarcinomas (Barrett's cancer). Gastrointest Endosc. 2007;65(1):3-10.

55. Pouw RE, Wirths K, Eisendrath P, et al. Efficacy of radiofrequency ablation combined with endoscopic resection for barrett's esophagus with early neoplasia. Clin Gastroenterol Hepatol. 2010;8(1):23-29.

56. Fleischer DE, Overholt BF, Sharma VK, et al. Endoscopic radiofrequency ablation for Barrett's esophagus: 5-year outcomes from a prospective multicenter trial. Endoscopy. 2010;42(10):781-789.

57. Kodama M, Kakegawa T. Treatment of superficial cancer of the esophagus: a summary of responses to a questionnaire on superficial cancer of the esophagus in Japan. Surgery. 1998;123(4):432-439.

58. Namasivayam V, Wang KK, Prasad GA. Endoscopic mucosal resection in the management of esophageal neoplasia: current status and future directions. Clin Gastroenterol Hepatol. 2010;8(9):743-754; quiz e796. 
59. Choi IJ, Kim CG, Chang HJ, Kim SG, Kook MC, Bae JM. The learning curve for EMR with circumferential mucosal incision in treating intramucosal gastric neoplasm. Gastrointest Endosc. 2005; 62(6):860-865.

60. Iddan G, Meron G, Glukhovsky A, Swain P. Wireless capsule endoscopy. Nature. 2000;405(6785):417.

61. Morgan D, Upchurch B, Draganov P, et al. Spiral enteroscopy: prospective US multicenter study in patients with small-bowel disorders. Gastrointest Endosc. 2010;72(5):992-998.

62. Frantz DJ, Dellon ES, Grimm IS, Morgan DR. Single-balloon enteroscopy: results from an initial experience at a US tertiary-care center. Gastrointest Endosc. 2010;72(2):422-426.

63. Gerson LB, Tokar J, Chiorean M, et al. Complications associated with double balloon enteroscopy at nine US centers. Clin Gastroenterol Hepatol. 2009;7(11):1177-1182, 1182.e1-e3.

64. Fisher L, Krinsky ML, Anderson MA, et al. The role of endoscopy in the management of obscure GI bleeding. Gastrointest Endosc. 2010; 72(3):471-479.

65. Gross SA, Stark ME. Initial experience with double-balloon enteroscopy at a US center. Gastrointest Endosc. 2008;67(6):890-897.

66. Gerson LB, Batenic MA, Newsom SL, Ross A, Semrad CE. Long-term outcomes after double-balloon enteroscopy for obscure gastrointestinal bleeding. Clin Gastroenterol Hepatol. 2009;7(6):664-669.
67. Fry LC, Neumann H, Kester D, et al. Small bowel polyps and tumours: endoscopic detection and treatment by double-balloon enteroscopy. Aliment Pharmacol Ther. 2008;29:135-142.

68. Chong AK, Chin BW, Meredith CG. Clinically significant small-bowel pathology identified by double-balloon enteroscopy but missed by capsule endoscopy. Gastrointest Endosc. 2006;64(3):445-449.

69. Ross A, Mehdizadeh S, Tokar J, et al. Double balloon enteroscopy detects small bowel mass lesions missed by capsule endoscopy. Dig Dis Sci. 2008;53(8):2140-2143.

70. Koornstra JJ, Fry L, Monkemuller K. ERCP with the balloonassisted enteroscopy technique: a systematic review. Dig Dis. 2008; 26(4):324-329.

71. Mehdizadeh S, Ross A, Gerson L, et al. What is the learning curve associated with double-balloon enteroscopy? Technical details and early experience in 6 US tertiary care centers. Gastrointest Endosc. 2006;64(5):740-750.

72. Multisociety Task Force on GI Training. Report of the Multisociety Task Force on GI Training. Am J Gastroenterol. 2009;104(11):2659-2663.

73. Friedman LS, Brandt LJ, Elta GH, et al. Report of the Multisociety Task Force on GI training. Gastrointest Endosc. 2009;70(5):823-827.
Advances in Medical Education and Practice

\section{Publish your work in this journal}

Advances in Medical Education and Practice is an international, peerreviewed, open access journal that aims to present and publish research on Medical Education covering medical, dental, nursing and allied healthcare professional education. The journal covers undergraduate education, postgraduate training and continuing medical education

\section{Dovepress}

including emerging trends and innovative models linking education, research, and healthcare services. The manuscript management system is completely online and includes a very quick and fair peer-review system. Visit http://www.dovepress.com/testimonials.php to read real quotes from published authors.

Submit your manuscript here: http://www.dovepress.com/advances-in-medical-education-and-practice-journal 